\title{
Dynamic and Thermodynamic Regulation of Ocean Warming*
}

\author{
TIM LI \\ Department of Meteorology, International Pacific Research Center, School of Ocean and Earth Science and Technology, \\ University of Hawaii, Honolulu, Hawaii \\ Timothy F. Hogan \\ Naval Research Laboratory, Monterey, California \\ C.-P. CHANG \\ Department of Meteorology, Naval Postgraduate School, Monterey, California
}

(Manuscript received 28 July 1998, in final form 7 June 1999)

\begin{abstract}
The relative roles of clouds, surface evaporation, and ocean heat transport in limiting maximum sea surface temperatures (SSTs) in the western Pacific warm pool are investigated by means of simple and intermediate coupled ocean-atmosphere models. The authors first take an analytical approach by constructing a conceptual two-box model that contains dynamic coupling among the Walker circulation, SST, and ocean thermocline and thermodynamic coupling, which includes shortwave and longwave cloud forcing and latent and sensible heat fluxes at the ocean surface. In a realistic parameter regime, the three mechanisms mentioned above are all essential in limiting the SSTs within the observed range. The lack of any one mechanism would lead to an equilibrium SST that is too high, although unstable warming due to the super greenhouse effect would not occur. The analysis of the surface heat balance from the simple box model indicates that in the western Pacific warm pool, cloud reflection has a dominant effect, followed by evaporation and ocean dynamics.

The simple model results are further evaluated numerically by using an intermediate coupled ocean-atmosphere model. With the forcing of the annual-mean solar radiation, this model is capable of simulating a realistic annual mean climate in the tropical Pacific. The authors then introduce an initial SST perturbation and examine how the perturbation evolves with time in the presence of clouds, surface evaporation, and ocean dynamic processes. Four experiments have been designed. In the first three experiments, each of the three processes is studied separately; in the last experiment, they are combined. The intermediate model results indicate that in the western Pacific warm pool, the largest negative feedback comes from the cloud shortwave radiation forcing, followed by the surface evaporation and ocean heat transport. The sensitivity of the model to various initial SST perturbation patterns is also investigated.
\end{abstract}

\section{Introduction}

The tropical Pacific is characterized by a strong eastwest sea surface temperature (SST) asymmetry, with the warmest water in the west and an equatorial cold tongue in the east. This SST asymmetry is reflected in the surface pressure gradient that drives an east-west equatorial atmospheric overturning, the Walker circulation (Bjerknes 1969). Atmospheric convection asso-

* School of Ocean and Earth Science and Technology Contribution Number 5243 and International Pacific Research Center Contribution Number 51 .

Corresponding author address: Dr. Tim Li, IPRC, SOEST, University of Hawaii, 1000 Pope Road, MSB 213, Honolulu, HI 96822. E-mail: li@soest.hawii.edu ciated with the rising branch of the Walker circulation is triggered primarily when SSTs exceed about $26.5^{\circ} \mathrm{C}$. Long-term records indicate that maximum SST in the warm pool is limited to below $31^{\circ} \mathrm{C}$. A central question is why this maximum SST is within a few degrees of the convection threshold.

Newell (1979) first addressed the issue by using a simple surface heat balance model. He showed that in the tropical ocean under a clear sky, the outgoing surface fluxes, which include longwave radiation and latent and sensible heat fluxes, are balanced by the incoming solar radiation at an SST of about $30^{\circ}-31^{\circ} \mathrm{C}$. With increased SST, the latent heat flux increases considerably. This prompted Newell to conclude that evaporation was the primary mechanism that limited the climatological SSTs to about $30^{\circ} \mathrm{C}$.

Newell's conclusion was modified by Graham and 
Barnett (1987), who noticed that in the upper range of SST, clouds associated with deep convection increase rapidly with SST. By taking into account the effect of clouds in the simple model of Newell, they obtained an equilibrium SST of $28^{\circ} \mathrm{C}$, a temperature coinciding with the peak of the observed SST population curve in the Tropics. From this result, they suggested that cloud reflection, in addition to the evaporative cooling, placed an upper limit for SSTs.

A more detailed analysis of cloud-SST feedback was conducted by Ramanathan and Collins (1991) using satellite and ship data obtained during the 1987 El Niño. They observed that in the upper range of SST, the greenhouse effect of water vapor increases with SST at a rate that exceeds the rate at which radiation is emitted from the ocean surface. As a result of this "super greenhouse effect," SSTs grow unbounded until the clouds become thick enough to shield the ocean from solar radiation and arrest further warming. Their major conclusion is that the SST is regulated mainly by a strong negative feedback of cirrus clouds induced by deep convection. Ramanathan and Collins (1992) further argued that surface evaporation could not function as a limiting mechanism in the warmest oceans because 1) evaporation adds moisture to the atmospheric column and thus enhances the super greenhouse effect and 2) along the equator, wind speeds in general tend to be smaller toward the warmer ocean.

The Ramanathan-Collins "thermostat" hypothesis was questioned by Wallace (1992) and Fu et al. (1992), who both argued that the deep convective clouds in the Tropics are generally associated with large-scale atmospheric circulation, not local SST alone, and that surface evaporation (due to the nonlinear nature of the Claussius-Clapyron equation) can effectively cool the ocean surface to the observed range. Hartmann and Michelsen (1993) noted that while the shortwave forcing in the convective regions is large, the area-averaged SST in the tropical Pacific shows no sensitivity to the basinaveraged cloud forcing. Analysis of four years of earth radiation budget by Arking and Ziskin (1994) showed that tropical clouds are largely affected by SSTs, but the influence of cloud radiative forcing on SST is less clear. Liu et al. (1994) argued that three-dimensional atmospheric circulation plays a more important role than the local cloud-SST relationship.

Sun and Liu (1996), Clement et al. (1996), Seager and Murtugudde (1997), and Liu and Huang (1997) proposed that ocean dynamics may play an important role in regulating tropical SSTs. These studies emphasized different aspects of ocean processes, including zonal and vertical heat transport at the equator (Sun and Liu 1996; Clement et al. 1996), upper-ocean thermocline displacement (Seager and Murtugudde 1997), and subtropicalequatorial heat exchange (Liu and Huang 1997). Using a simple box model, Sun and Liu (1996) demonstrated that even without cloud reflection and surface evaporation, ocean dynamic processes alone (through zonal and vertical heat transport) can act as a thermostat to regulate tropical SSTs.

Waliser (1996) investigated the effect of transient atmospheric motion (primarily intraseasonal oscillations) on the formation of ocean hot spots. He defined hot ocean spots as regions where SST is greater than $29.75^{\circ} \mathrm{C}$. Using a variety of data sources [including satellite observations, Consolidated Ocean Atmosphere Data Set (COADS), National Centers for Environmental Prediction (NCEP) and European Centre for MediumRange Weather Forecasts (ECMWF) reanalyses], he examined composites of the atmospheric and oceanic conditions before and after a hot spot is formed and found that the descending (ascending) phase of the MaddenJulian oscillation (MJO) is often associated with the formation (decay) of the hot spots. He found that the effect of cloud shortwave forcing in general exceeds that of evaporation by a factor of 2 .

These studies and many others have greatly advanced our understanding of the formation of the warm pool and the mechanisms that regulate tropical SSTs. However, some key issues remain to be resolved. For instance, several of the individual studies (e.g., Ramanathan and Collins 1991; Wallace 1992; Sun and Liu 1996) isolated different processes. Some of the studies (e.g., Waliser and Graham 1993) have limited applicability because their conclusions were derived based on local, not coherent, dynamic relationships. Others (e.g., Liu et al. 1994) are actually directed toward the regulation mechanisms of the annual cycle and El NiñoSouthern Oscillation (ENSO) which do not necessarily reflect the processes regulating maximum SSTs in the warm pool. The large-scale motion associated with MJO can indeed change SSTs on a shorter (intraseasonal) timescale, but its mean effect on long-term climate is unclear.

The present study is an attempt to overcome some of the above shortcomings by considering possible SSTregulation mechanisms in a unified dynamic framework. We shall investigate the relative roles of these processes (cloud vs surface evaporation vs ocean dynamics) in limiting maximum SSTs in the Tropics. We are particularly interested in whether each individual mechanism is sufficient to limit the SSTs to the observed range or whether it is necessary to require two or all three mechanisms to work together. To achieve the goal, we take both an analytical and a numerical approach. In section 2 , a simple analytical two-box model is constructed to obtain some preliminary results. In section 3 , these results are compared with those obtained from a more sophisticated, intermediate coupled ocean-atmosphere model. A summary is given in section 4 .

\section{Analysis of a simple two-box model}

In this section, a simple analytical model is used to understand processes that limit maximum climatological SSTs in the western Pacific warm pool. 


\section{a. Model}

A simple coupled ocean-atmosphere model is constructed with the Lindzen-Nigam (1987) model as its atmospheric component and the Cane-Zebiak model (Cane 1979; Zebiak and Cane 1987) as its oceanic component. For simplicity, the ocean surface is divided into two equal-volume boxes (see Fig. 1), with $T_{1}$ and $T_{2}$ representing the averaged temperature over the western and eastern equatorial Pacific, respectively. The time change rate of the SST in the two boxes is determined by horizontal and vertical temperature advection and the surface heat fluxes, which include shortwave and longwave radiation and latent and sensible heat fluxes, that is,

$$
\begin{aligned}
& \frac{d T_{1}}{d t}=-u_{c} \frac{\left(T_{2}-T_{1}\right)}{L_{\mathrm{x}}}+\frac{Q_{1}}{\rho C_{w} h} \\
& \frac{d T_{2}}{d t}=-w_{e} \frac{\left(T_{2}-T_{\mathrm{sub}}\right)}{h}+\frac{Q_{2}}{\rho C_{w} h},
\end{aligned}
$$

where $u_{c}$ denotes the zonal ocean current velocity in the central Pacific; $w_{e}$ denotes the vertical velocity at the base of the mixed layer in the eastern Pacific; $L_{x}$ and $h$ denote the half length of the Pacific basin and the depth of an ocean mixed layer, respectively; $T_{\text {sub }}$ is the ocean subsurface temperature; $Q$ represents the net heat flux at the ocean surface; subscripts denote box 1 and 2 , respectively; $\rho$ denotes the density of water; and $C_{w}$ the specific heat of water.

The zonal SST gradients between $T_{1}$ and $T_{2}$ determine the surface zonal wind stress in the central Pacific (Lindzen and Nigam 1987), which further drives the ocean Ekman current and upwelling through surface layer ocean divergence (Zebiak and Cane 1987). Therefore, we have

$$
\begin{aligned}
\tau^{(x)} & =\mu U_{c}=\mu \frac{A}{r_{a} L_{x}}\left(T_{2}-T_{1}\right), \\
r_{o} u_{c} & =\frac{\tau^{(x)}}{\rho h}=\frac{\mu A}{\rho h r_{a} L_{x}}\left(T_{2}-T_{1}\right), \\
w_{e} & =-\frac{h(H-h)}{H} \frac{u_{c}}{L_{x}}=-\frac{h(H-h) \alpha}{H L_{x}}\left(T_{2}-T_{1}\right),
\end{aligned}
$$

where $\mu=\rho_{a} C_{D} V_{0}$ is a surface wind stress coefficient, $\rho_{a}$ is the density of surface air, $C_{D}$ is the drag coefficient, $V_{0}$ is a constant wind speed, $r_{a}$ and $r_{o}$ denote the Rayleigh friction coefficients in the atmospheric and oceanic boundary layers, A represents the SST-gradient momentum forcing coefficient (Wang and Li 1993), $H$ is the mean depth of the ocean thermocline across the equatorial Pacific, and $\alpha=(\mu A) / \rho h r_{a} r_{o} L_{x}$.

Following the scale analysis by Neelin (1991) and Li (1997b), the zonal gradient of the ocean thermocline at the equator is in a Sverdrup balance with the zonal wind stress forcing. Therefore, we have

$$
T_{\text {sub }}=T_{c}+\gamma \eta=T_{c}-\beta\left(T_{1}-T_{2}\right),
$$

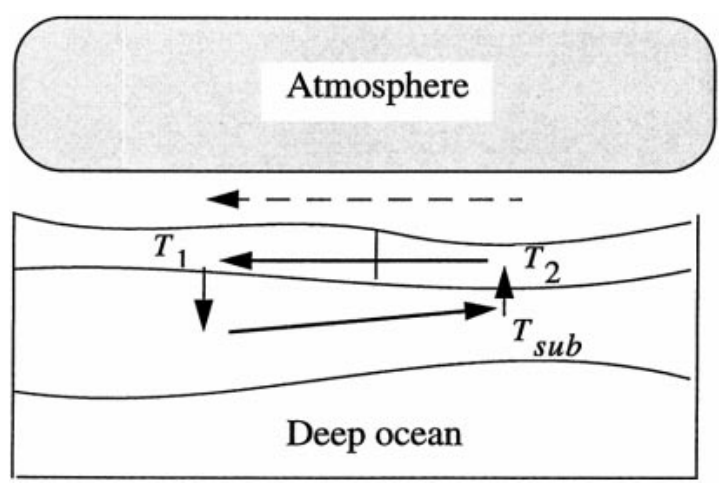

FIG. 1. Schematic illustration of the two-box model (after Sun 1997).

where $T_{c}$ denotes a constant zonally averaged ocean temperature at the base of the ocean mixed layer, $\eta$ represents the thermocline depth anomaly, $\gamma$ is a coefficient representing the strength of SST-thermocline feedback, $\beta=(\gamma \mu A) / 2 \rho r_{a} c_{0}^{2}$, and $c_{0}$ is the first baroclinic mode gravity wave speed in the upper ocean.

The net heat flux at the ocean surface contains solar radiation, longwave radiation, and latent and sensible heat fluxes, which may be expressed as

$$
Q=S-E+G-W
$$

where $S$ is the shortwave radiation at the surface; $E$ and $G$ are upward and downward longwave radiative fluxes, respectively; and $W$ is latent and sensible heat fluxes.

The shortwave radiation at the ocean surface may be further divided into two terms:

$$
S=S_{c}+C_{s},
$$

where $S_{c}$ denotes the clear-sky solar radiation, which can be calculated based on the annual mean solar radiation at the top of the atmosphere $\left(424 \mathrm{~W} \mathrm{~m}^{-2}\right)$ with reductions for scattering (0.08), absorption $(0.22)$, and ocean albedo (0.06) (Payne 1972; Liou 1980); and $C_{s}$ $<0$ denotes the cloud shortwave radiation forcing.

Following Kiehl and Briegleb (1992) and Waliser and Graham (1993), the upward and downward longwave radiative fluxes may be written as

$$
\begin{aligned}
& E=0.94 \sigma T^{4} \\
& G=10.64 T-2800 .
\end{aligned}
$$

In (2.10), the greenhouse effect of water vapor and clouds has been parameterized through SST.

The surface latent and sensible heat fluxes depend on the total wind speed and air-sea specific humidity and temperature differences:

$$
W=\mu L\left(q_{s}-q_{a}\right)+\mu C_{p}\left(T-T_{a}\right),
$$

where $C_{p}$ is the specific heat of the air and $L$ is the latent heat. In (2.11), we have assumed a constant wind speed because the current model only predicts the zonal wind component in the central Pacific. (For the control case, 
the calculated wind speed in the central Pacific is 5.2 $\mathrm{m} \mathrm{s}^{-1}$, which is close to the specified constant wind speed, $5 \mathrm{~m} \mathrm{~s}^{-1}$.) In section $2 \mathrm{c}$, we will examine the sensitivity of the model solution to the wind speed. In subsequent intermediate coupled experiments, we will abandon the constraint by using model-predicted surface winds.

Different from the conceptual model of Newell (1979), who used a constant air specific humidity in the surface evaporation calculation, we calculate both air surface temperature and specific humidity based on an empirical observational analysis ( $\mathrm{Li}$ and Wang 1994; Wang et al. 1995):

$$
\begin{aligned}
& q_{a}=10^{-3}[0.972 T-8.92] \\
& T_{a}=1.03 T-1.32,
\end{aligned}
$$

where $T$ is in degrees Celsius. The above two equations are derived based on a climatological monthly mean COADS date analysis with a sample size over 20000 . The correlation coefficients are 0.99 and 0.96 , respectively.

The net surface heat flux can be approximately expressed as a linear Taylor expansion with respect to a reference temperature, $T_{0}$, that is,

$$
\begin{aligned}
Q & =Q_{0}+\left.\frac{\partial Q}{\partial T}\right|_{T=T_{0}}\left(T-T_{0}\right) \\
& =Q_{0}+\sigma\left(T-T_{0}\right),
\end{aligned}
$$

where $Q_{0}=S_{c}-E\left(T_{0}\right)+G\left(T_{0}\right)-W\left(T_{0}\right)$ denotes the net heat flux at the ocean surface at $T_{0}$ and

$$
\sigma=\left.\left(\frac{\partial C_{S}}{\partial T}-\frac{\partial E}{\partial T}+\frac{\partial G}{\partial T}-\frac{\partial W}{\partial T}\right)\right|_{T_{0}}
$$

represents the rate of the net heat flux changes with respect to the SST change at $T=T_{0}$.

Equations (2.1)-(2.14) form a simple dynamic system for the annual mean climate in the Pacific. The major differences between the current model and that of Sun and Liu (1996) lie in 1) the treatment of surface heat flux processes in the SST equations (Sun and Liu assumed a Newtonian damping term that forces SST toward a specified constant equilibrium temperature, whereas in the current model, we calculate the equilibrium temperature through ocean dynamic and thermodynamic processes; the thermodynamic processes include shortwave and longwave radiation and latent and sensible heat fluxes); 2) the inclusion of ocean thermocline effect on SST; and 3) a unified dynamic framework that combines the existing three SST-regulation mechanisms.

The behavior of the simple dynamic system depends on several key parameters. Among them are the air-sea coupling coefficient, atmospheric and oceanic boundary layer friction coefficients, SST-thermocline feedback coefficient, and cloud shortwave radiation forcing co-

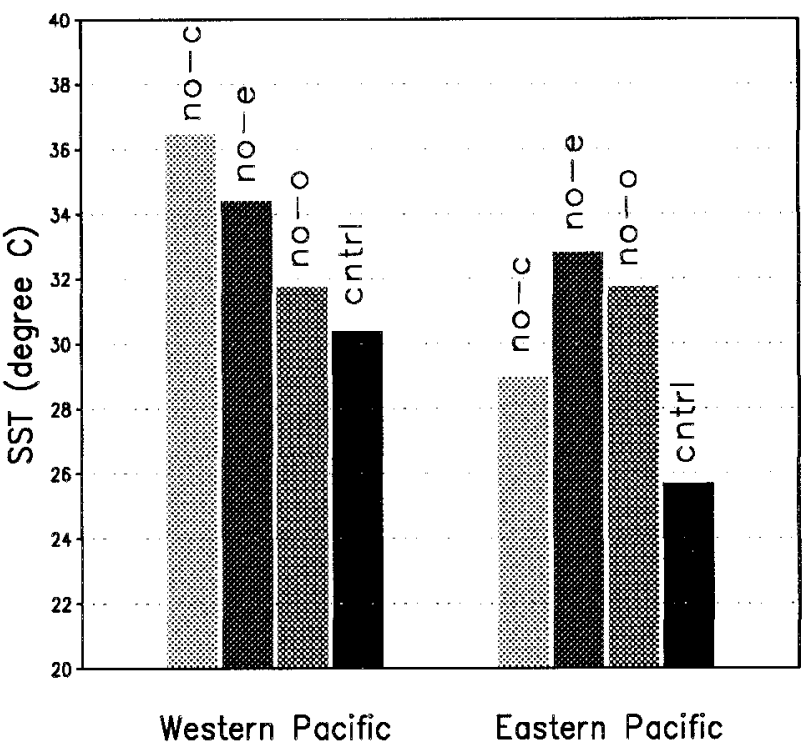

FIG. 2. Equilibrium temperatures $T_{1}$ and $T_{2}$ (unit: ${ }^{\circ} \mathrm{C}$ ) for the control run (cntrl), no-cloud reflection case (no-c), no-evaporation feedback case (no-e), and no-ocean heat transport case (no-o).

efficient. The following standard parameter values are set for a control run: $T_{c}=18^{\circ} \mathrm{C}, Q_{0}=110 \mathrm{~W} \mathrm{~m}^{-2}, h$ $=25 \mathrm{~m}, H=150 \mathrm{~m}, r_{a}=r_{o}=0.5$ day $^{-1}, c_{0}=3 \mathrm{~m}$ $\mathrm{s}^{-1}, V_{0}=5 \mathrm{~m} \mathrm{~s}^{-1}, \gamma=0.05^{\circ} \mathrm{C} \mathrm{m}^{-1}, L_{x}=70^{\circ}, A=51$ $\mathrm{m}^{2} \mathrm{~s}^{-2} \mathrm{~K}^{-1}, C_{D}=1.5 \times 10^{-3}, \mathrm{~T}_{0}=300 \mathrm{~K}, \partial C_{s} / \partial T=$ $-19 \mathrm{~W} \mathrm{~m}^{-2} K^{-1}$. In the next sections, we will analyze the model solutions and examine the model's sensitivity to some of key parameters described above.

\section{b. Analytical solutions}

Besides a motionless equilibrium solution $T_{1}=T_{2}=$ $T_{0}-\left(Q_{0} / \sigma\right)$, which is unstable, the control run has an equilibrium temperature solution of $30.4^{\circ} \mathrm{C}$ for the western Pacific and $25.7^{\circ} \mathrm{C}$ for the eastern Pacific (Fig. 2). These values agree well with the long-term climatology.

The relative roles of the cloud, surface evaporation, and ocean dynamics were studied through three experiments, each of which excludes one of the three mechanisms. The results (Fig. 2) show that a temperature equilibrium can be reached by any one of the three mechanisms. In the absence of the cloud-SST feedback, the effective suppression of the vapor and cloud super greenhouse effect warming by the surface latent heat flux is readily seen through the comparison of heat flux change rates at the reference temperature $T_{0}$, since $(\partial G / \partial T)-(\partial E / \partial T)=10.64-5.76=4.88 \mathrm{~W} \mathrm{~m}^{-2} \mathrm{~K}^{-1}$ while $-(\partial W / \partial T)=-8.9 \mathrm{~W} \mathrm{~m}^{-2} \mathrm{~K}^{-1}$. The effective suppression by the ocean heat transport may also be understood, since in this process the heat flux required for a unit temperature change may be measured by $\partial O / \partial T=-\left[\rho c_{w} h \alpha\left(T_{1}-T_{2}\right)^{2}\right] / L_{x}\left(T_{1}-T_{0}\right)=-7.9 \mathrm{~W}$ $\mathrm{m}^{-2} \mathrm{~K}^{-1}$, which also exceeds the super greenhouse effect. 


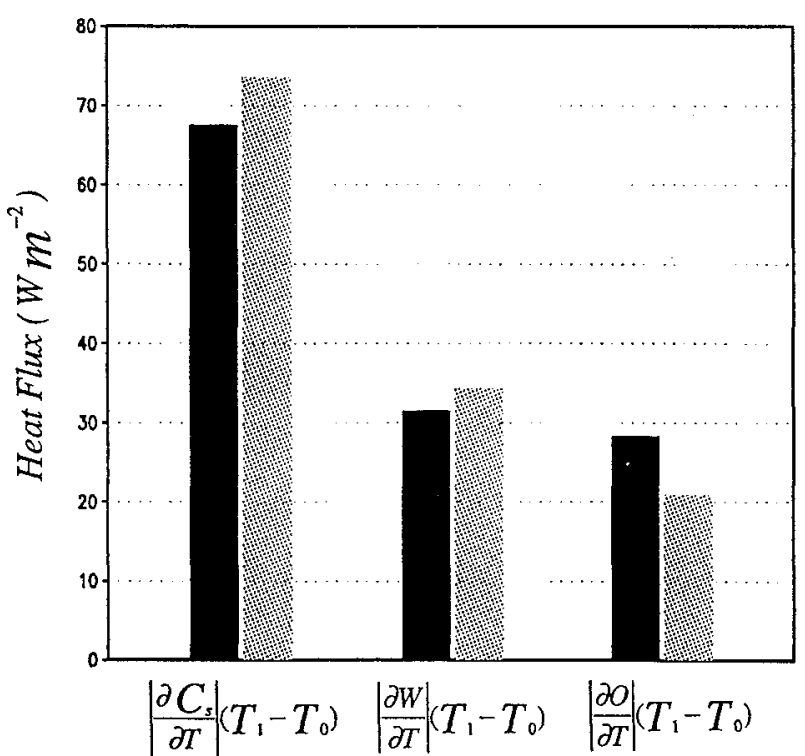

FIG. 3. Heat flux losses (unit: $\mathrm{W} \mathrm{m}^{-2}$ ) associated with the shortwave cloud forcing, surface evaporation, and ocean dynamic processes in the western Pacific for the control run (dark shaded) and the case of $\gamma=0$ (light shaded).

Figure 2 indicates that all three mechanisms are important in obtaining the observed climatological SST values. The equilibrium temperature in the western $\mathrm{Pa}-$ cific would reach $36^{\circ} \mathrm{C}$ without the cloud reflection, $34^{\circ} \mathrm{C}$ without the surface evaporation, and $32^{\circ} \mathrm{C}$ without the ocean heat transport. The discrepancies are all large in the eastern Pacific.

The relative roles can be further analyzed by diagnosing the surface heat budget in the SST equation [Eq. (2.1)]. Denoting $-\left(\partial C_{s} / \partial T\right)\left(T_{1}-T_{0}\right)$ as the surface heat flux reduction due to the cloud shortwave forcing, $(\partial W / \partial T)\left(T_{1}-T_{0}\right)$ as the latent heat flux increase as the SST increases from $T_{0}$ to $T_{1}$, and $-\rho C_{w} h \alpha\left(T_{1}-T_{2}\right)^{2} / L_{x}$ as the amount of the ocean heat transport, one can readily see (Fig. 3) that as the SST increases from $T_{0}$ to $T_{1}$, the solar radiation decreases by $67 \mathrm{~W} \mathrm{~m}^{-2}$ while the latent heat flux increases by $31 \mathrm{~W} \mathrm{~m}^{-2}$. Meanwhile, the ocean transports $28 \mathrm{~W} \mathrm{~m}^{-2}$ of heat from the eastern Pacific to the western Pacific. Note that the calculated shortwave cloud forcing agrees well with recent International Satellite Cloud Climatology Project (ISCCP) data analyses by Laszlo and Pinker (1993), who reported an average of cloud shortwave forcing of $60-80 \mathrm{~W} \mathrm{~m}^{-2}$ over the equatorial western Pacific. Thus, the effect of the cloud reflection has a large contribution and is comparable to the combined effect of the surface evaporation and ocean dynamics.

\section{c. Sensitivity test}

To test the sensitivity of the model, we first examine two key parameters in the model: $\partial C_{s} / \partial T$ and $V_{0}$. The former reflects the strength of the cloud-SST feedback

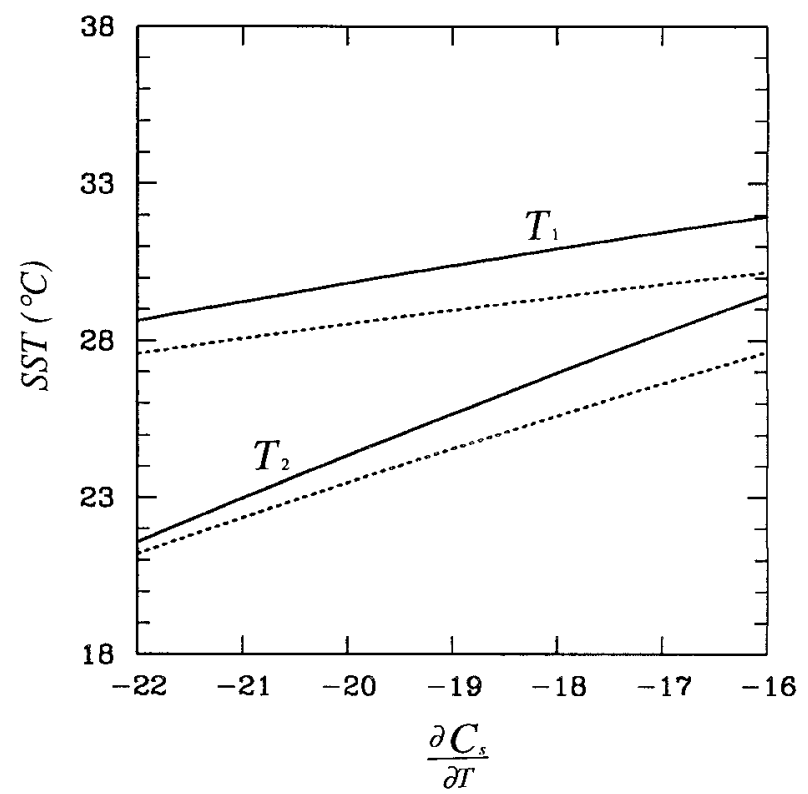

FIG. 4. Dependence of equilibrium temperatures $T_{1}$ and $T_{2}$ (unit: $\left.{ }^{\circ} \mathrm{C}\right)$ to the cloud-SST feedback coefficient, $\partial C_{s} / \partial T$, for the control case when $V_{0}=5 \mathrm{~m} \mathrm{~s}^{-1}$ (solid lines) and a case with $V_{0}=6 \mathrm{~m} \mathrm{~s}^{-1}$ (dotted lines).

whereas the latter influences the intensity of the surface latent and sensible heat fluxes. The range of $\partial C_{s} / \partial T$ is based on a linear fit of the satellite analysis by Ramanathan and Collins (1991, their Fig. 4). As expected, equilibrium temperatures $T_{1}$ and $T_{2}$ increase with decreasing magnitude of $\partial C_{s} / \partial T$ (Fig. 4) and increasing $V_{0}$. An increase of $1 \mathrm{~m} \mathrm{~s}^{-1}$ in the wind speed corresponds approximately to a decrease of $1^{\circ} \mathrm{C}$ in the equilibrium temperatures.

Our sensitivity experiments further show that the upper-ocean thermocline movement [which is not considered in Sun and Liu (1996) and Clement et al. (1996)] is an important process that influences the ocean heat transport because it changes subsurface ocean temperatures and thus changes vertical temperature gradients. To illustrate its role, we conducted an additional experiment by setting $\gamma=0$. The result, as shown in Fig. 3 (the light shaded bars), indicates that the ocean heat transport is reduced by one-third of its original amplitude. This reduction is offset by the increase in the other two effects.

We further examined the sensitivity of the model to the mean depth of the ocean mixed layer $h$ and the SSTthermocline feedback coefficient $\gamma$ (see Fig. 5). It turns out that the cloud shortwave forcing and evaporative flux decrease with increased $h$ and $\gamma$, while ocean transport has an opposite tendency. The physical interpretation of this result is simple. The effect of heat fluxes on SST is always reduced when the ocean mixed layer thickens. A stronger ocean heat transport occurs when the subsurface temperature change associated with the thermocline displacement is considered. 

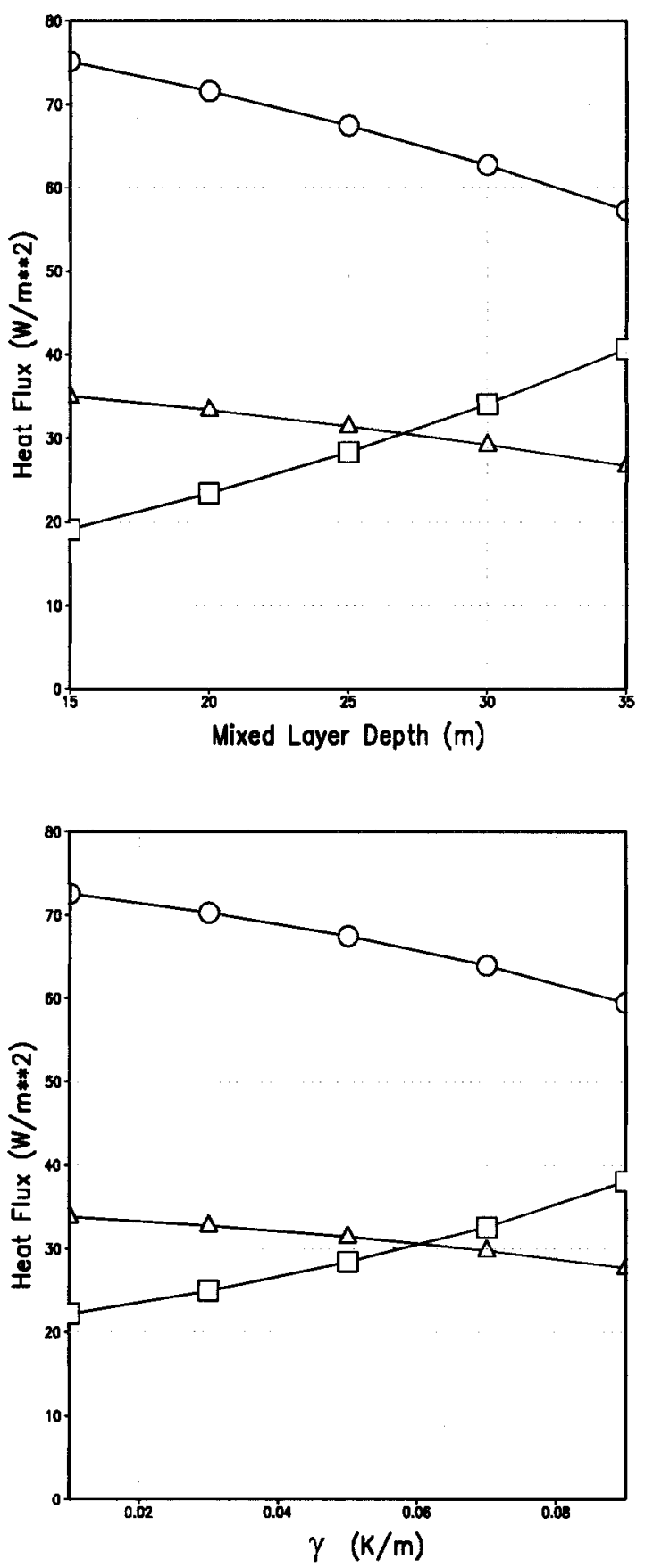

FIG. 5. Dependence of cloud shortwave forcing (circle), evaporation (triangle), and ocean heat transport (square) (unit: $\mathrm{W} \mathrm{m}^{-2}$ ) on the ocean mixed layer depth, $h$ (top panel), and SST-thermocline feedback coefficient, $\gamma$ (bottom panel).

\section{Intermediate coupled model experiments}

In the previous simple two-box model, we assumed a constant surface wind speed in the latent and sensible heat flux calculation and a fixed cloud-SST feedback coefficient, $\partial C_{s} / \partial T$, based on the Ramanathan-Collins satellite analysis. We now relax these constraints/as- sumptions by using an intermediate coupled model that predicts both clouds and surface winds.

\section{a. Model description}

Unlike previous intermediate coupled models (e.g., Cane and Zebiak 1985; Anderson and McCreary 1985) that simulate only anomaly fields, we use an intermediate model that is capable of simulating both climatological mean and anomaly fields.

The atmospheric component of the coupled model was developed by Li and Wang (1994). A brief description of the model and model parameters is given in the appendix. Based on the observational evidence that the annual variation of the vertically averaged lapse rate plays an important role in determining sea level pressure (SLP), this atmospheric model first calculates the vertically averaged lapse rate from SST using an empirical formula derived from observations [Eq. (A.4)]. The sea level pressure is then determined from a vertical integration of the hydrostatic equation and the equation of state [Eq. (A.3)]. Once the sea level pressure is determined, the surface winds are computed assuming a linear momentum balance with an anisotropic, latitudedependent Rayleigh friction [Eqs. (A.1) and (A.2)]. Despite its simplicity, this atmospheric model is capable of simulating not only the interannual variation of surface winds but also the climatological annual cycle when forced with the observed tropical Pacific SST.

The oceanic component is a Cane-Zebiak type model (Cane 1979; Zebiak and Cane 1987). It features a linear reduced gravity upper-ocean dynamics with a varying thermocline that separates the surface warm water and deep-ocean cold water [Eqs. (A.6) and (A.7)]. Embedded into the reduced gravity upper ocean is a constant depth, linear Ekman layer, which captures the intensity of wind-driven surface currents and associated vertical motion [Eqs. (A.9)-(A.11)]. The subsurface temperature is parameterized in terms of changes in the thermocline depth [Eq. (A.12)]. The model was originally developed to predict changes in anomaly SST and was coupled with a Gill-type anomaly atmospheric model for ENSO simulations (Cane and Zebiak 1985; Zebiak and Cane 1987). It has been subsequently modified and used in climatological annual mean and annual cycle studies (e.g., Seager et al. 1988; Chang 1994; Li and Philander 1996; Li 1997a).

The atmospheric and oceanic components are coupled using a nonlinear relation between surface wind stresses and wind speeds, that is,

$$
\boldsymbol{\tau}=\rho C_{D}|\mathbf{V}| \mathbf{V}
$$

where $C_{D}$ is a drag coefficient and $\mathbf{V}$ is atmospheric surface wind.

The shortwave and longwave radiative fluxes at the ocean surface may be expressed as 


$$
\begin{aligned}
Q_{\mathrm{sw}}= & Q_{0}(1-\zeta)[1-(a+b n) n] \\
Q_{\mathrm{lw}}= & 0.97 \sigma T_{a}^{4}(0.39-0.05 \sqrt{e})\left(1-c n^{2}\right) \\
& +3.88 \sigma T_{a}^{3}\left(T_{S}-T_{a}\right),
\end{aligned}
$$

where $Q_{0}$ is the annual-mean direct and diffuse maximum solar flux and is a function of latitude (Budyko and Miller 1974); $n$ is the cloudiness (in fraction); $\zeta=$ 0.06 denotes the albedo of the ocean surface; $b=0.38$ is a constant; $a$ and $c$ are coefficients varying with latitude; $T_{a}$ and $T_{s}$ are air and sea surface temperatures, respectively; $e$ is the water vapor pressure at the sea surface; and $\sigma$ is the Stefan-Boltzmann constant.

The cloudiness in the model is parameterized from the precipitation rate, which is calculated based on largescale moisture convergence and surface evaporation [Eq. (A.5)]:

$$
n=n_{0}+m P_{r},
$$

where $n_{0}$ denotes the mean cloud amount that is not associated with deep convection and $m$ is a tuned coefficient. The value of $m$ is set to be $0.4 / 15$ based on the observational fact that a climatological monthly mean rainfall of $450 \mathrm{~mm}$ (or $15 \mathrm{~mm} \mathrm{day}^{-1}$ ) over the tropical oceans corresponds approximately to a mean cloud fraction of 40\% (Xie and Arkin 1996; Oberhuber 1988). For simplicity, a constant value of $n_{0}=0.1$ is used.

The latent and sensible heat fluxes at the ocean surface are calculated according to bulk aerodynamic formulas:

$$
\begin{aligned}
& Q_{\mathrm{lh}}=\rho_{a} c_{D}|\mathbf{V}| L\left(q_{s}-q_{a}\right) \\
& Q_{\mathrm{sh}}=\rho_{a} c_{D}|\mathbf{V}| c_{p}\left(T_{s}-T_{a}\right),
\end{aligned}
$$

where $\rho_{a}=1.2 \mathrm{~kg} \mathrm{~m}^{-3}, L=2.5 \times 10^{6} \mathrm{~J} \mathrm{~kg}^{-1}$, and $c_{p}$ $=1004 \mathrm{~J} \mathrm{~kg}^{-1} \mathrm{~K}^{-1}$. The saturation specific humidity $q_{s}$ is a function of $T_{s}$ and is calculated from the ClaussiausClapyron equation. The surface air specific humidity $q_{a}$ and the air temperature $T_{a}$ are calculated from Eqs. (2.12)-(2.13).

\section{b. Equilibrium solutions}

When forced by the annual-mean solar radiation, the model reaches an equilibrium state after a 5-yr integration. Figure 6 a shows the equilibrium solutions for SST, surface wind, rainfall, and thermocline depth. The simulated annual-mean climate reasonably approximates the observed long-term climatology in the tropical Pacific (Fig. 6b). The east-west asymmetry in the SST field, characterized by the warm pool (with a maximum temperature of greater than $30^{\circ} \mathrm{C}$ ) in the western Pacific and the cold tongue (with a minimum temperature of about $23^{\circ} \mathrm{C}$ ) in the eastern Pacific, is modeled reasonably well. The east-west SST gradient drives the atmospheric Walker circulation so that winds at the surface are easterlies. The easterly trades converge onto the warmest water in the western Pacific over which convection occurs. The clouds associated with the convection affect the SST by altering net shortwave and longwave radiation at the surface. In addition, the trades also influence the SSTs through surface evaporation and ocean dynamics (by inducing three-dimensional ocean currents and thermocline variations). A strong east-west tilt appears in the mean thermocline depth field at the equator, with the thermocline more shallow in the eastern Pacific and deeper in the western Pacific.

In addition to the east-west asymmetry, there is also a north-south asymmetry. In the eastern Pacific, southerly trades cross the equator and converge onto the intertropical convergence zone (ITCZ). Consistent with this convergence, maximum precipitation appears to the north of the equator. Since the annual-mean solar radiation is approximately symmetric about the equator, the north-south asymmetry results from coupled oceanatmosphere interactions (Philander et al. 1996; Li 1997a).

The diagnosis of the annual-mean surface heat budget indicates that the SST is primarily determined by the shortwave radiation and surface evaporation. Longwave flux and ocean dynamic processes, on the other hand, also play an important role. The net surface shortwave radiation (see Fig. 7) in the western Pacific is about $200 \mathrm{~W} \mathrm{~m}^{-2}$, which agrees well with Pinker and Laszlo's (1992) satellite retrieval. The averaged net ocean heat transport in the western equatorial Pacific is less than $30 \mathrm{~W} \mathrm{~m}^{-2}$, which is consistent with observations (Oberhuber 1988) and coupled GCM simulations (e.g., Schneider et al. 1996). The comparison between the shortwave radiation over the western Pacific (where deep convection occurs) and eastern Pacific (cloud free) reveals that the cloud shortwave forcing is about $72 \mathrm{~W}$ $\mathrm{m}^{-2}$ for a mean temperature difference of $4^{\circ} \mathrm{C}$. This agrees reasonably with a $75 \mathrm{~W} \mathrm{~m}^{-2}$ solar difference derived from the Earth Radiation Budget Experiment (ERBE) data between convective and trade wind regions. The solar radiation difference corresponds to a heat flux change rate of $18 \mathrm{~W} \mathrm{~m}^{-2} \mathrm{~K}^{-1}$, which is close to the $19 \mathrm{~W} \mathrm{~m}^{-2} \mathrm{~K}^{-1}$ reported by Ramanathan and Collins (1991). Surface evaporation is larger in the eastern Pacific than in the western Pacific even though the SST is lower in the eastern Pacific. This is because of greater wind speeds in the cold tongue region. Among all terms, sensible heat flux is smallest (about $10 \mathrm{~W} \mathrm{~m}^{-2}$ ). Although the SST is higher, the net outgoing longwave flux is smaller in the western Pacific due to the longwave radiation forcing of clouds and atmospheric water vapor.

\section{c. Sensitivity experiments}

The results of section $3 \mathrm{~b}$ demonstrate that the intermediate coupled model is capable of simulating a realistic annual-mean climate. In this section, we investigate the specific processes that regulate maximum SSTs in the warm pool. Our strategy is to introduce an 

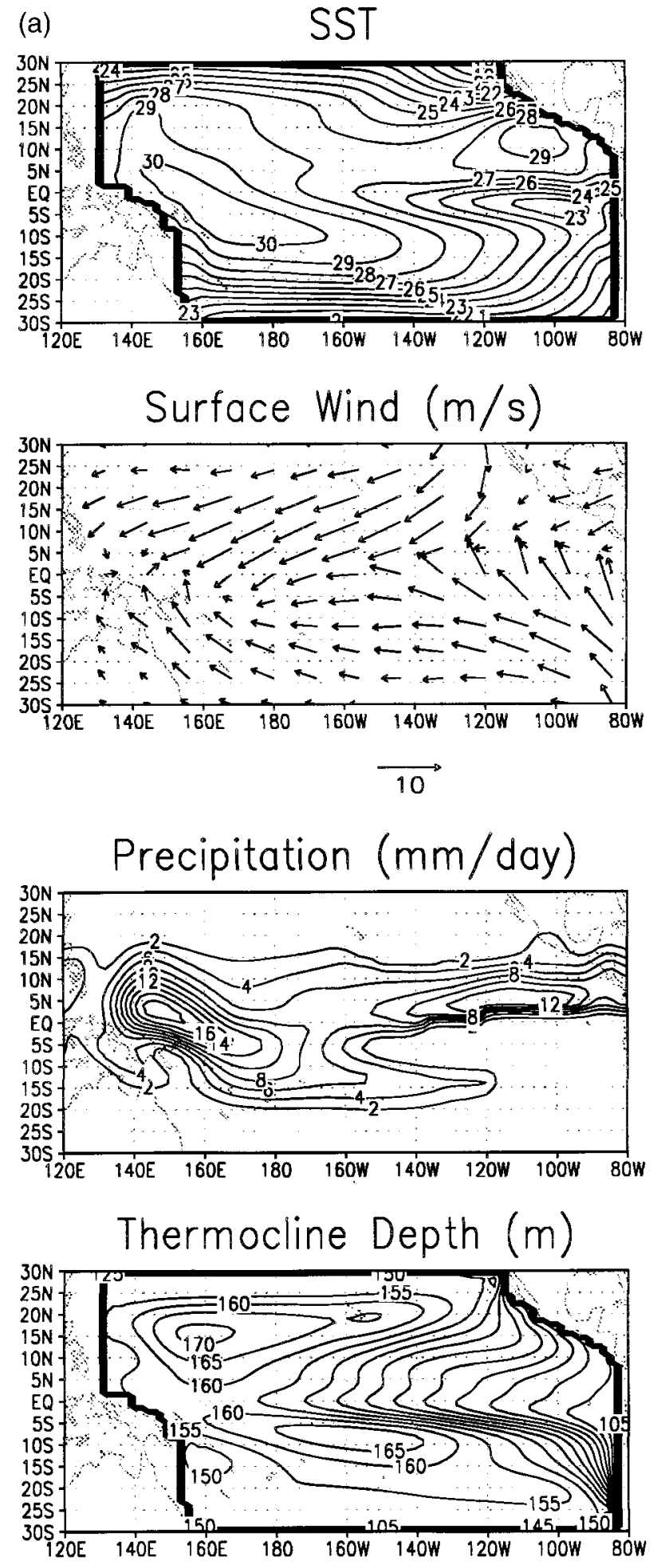

initial SST perturbation in the warm pool region and examine how the perturbation evolves in the presence of clouds, evaporation, and ocean dynamical processes. The following four experiments are designed. To study
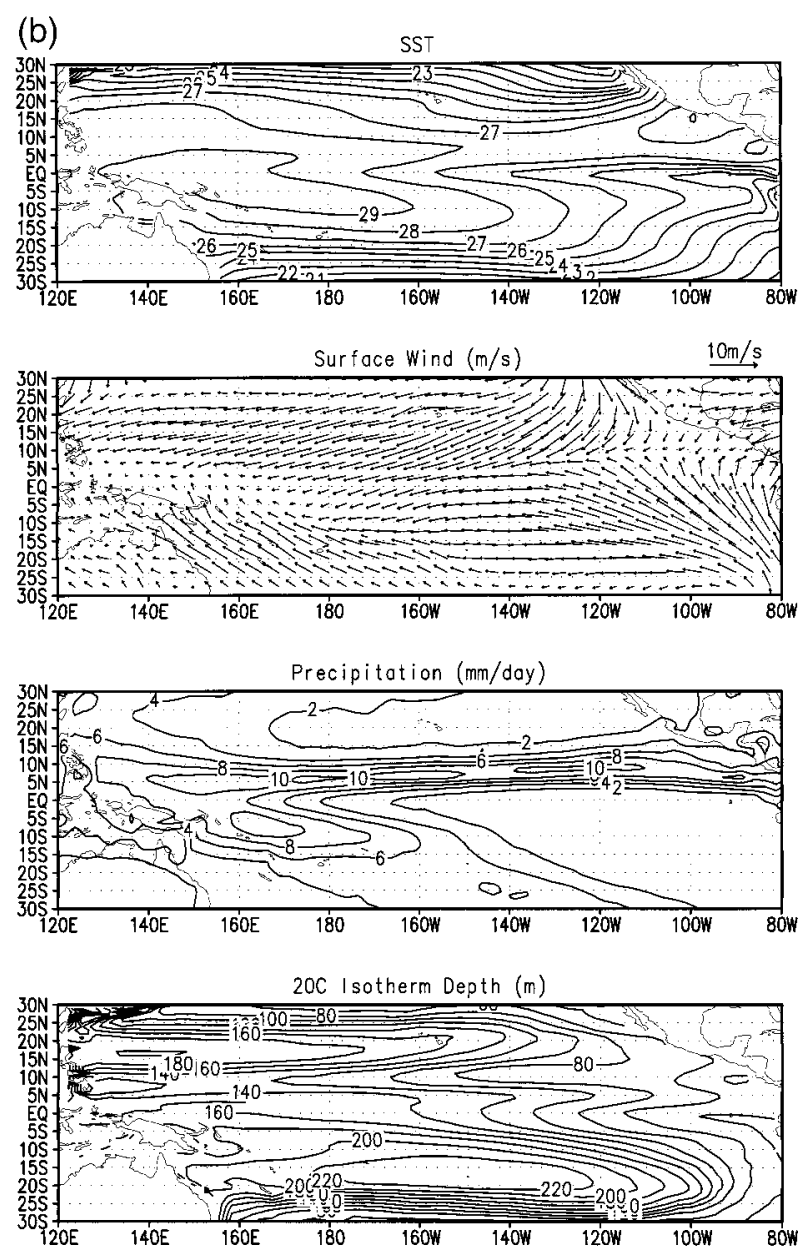

FIG. 6. (a) Equilibrium solutions for the annual mean SST, surface wind, precipitation rate, and ocean thermocline depth from the intermediate coupled model; and (b) observed counterparts for the annual mean SST, wind, precipitation, and depth of $20^{\circ} \mathrm{C}$ ocean isotherm.

the role of cloud reflection (case A), we specify timeindependent longwave, latent, and sensible heat fluxes, and ocean dynamic terms, which are derived from the previous annual-mean climate case, while calculating 


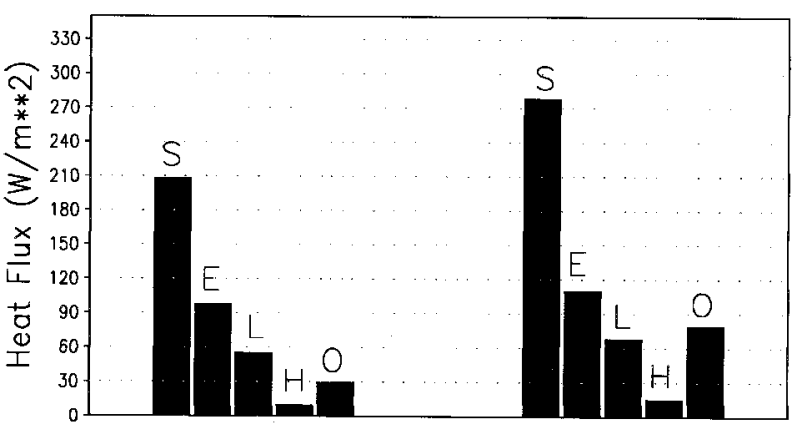

Western Pacific

Eastern Pacific

FIG. 7. Annual-mean surface heat budget diagnosed from the intermediate coupled model for the equatorial western Pacific (averaged over $5^{\circ} \mathrm{S}-5^{\circ} \mathrm{N}$ and $140^{\circ} \mathrm{E}-180^{\circ}$ ) and eastern Pacific (averaged over $5^{\circ} \mathrm{S}-5^{\circ} \mathrm{N}$ and $\left.140^{\circ}-100^{\circ} \mathrm{W}\right)$. The $\mathrm{S}$ denotes the surface shortwave radiation, $\mathrm{E}$ surface evaporation, $\mathrm{L}$ net longwave radiation, $\mathrm{H}$ sensible heat flux, and $\mathrm{O}$ ocean heat transport (units: $\mathrm{W} \mathrm{m}^{-2}$ ).

the cloud shortwave forcing at each time step. In cases $\mathrm{B}$ and $\mathrm{C}$, we examine the role of surface evaporation and ocean dynamic processes, respectively. In case D, all three processes are considered.

Superposed on the equilibrium annual mean SST field $\bar{T}$, an SST perturbation (see Fig. 8) is introduced initially, which has the following formula:

$$
T^{\prime}= \begin{cases}\left(\bar{T}-29^{\circ} \mathrm{C}\right) \times 5, & \bar{T}>29^{\circ} \mathrm{C} \\ 0, & \bar{T} \leq 29^{\circ} \mathrm{C} .\end{cases}
$$

Figure 9 illustrates the time evolution of maximum SSTs in the four cases. In all cases, the initial SST perturbation is reduced, and the model reaches an equilibrium state. The results suggest that the annual-mean climate is stable to the perturbation in the presence of each of the mechanisms. The resulting equilibrium temperature is $31.5^{\circ} \mathrm{C}$ for case $\mathrm{A}, 33.2^{\circ} \mathrm{C}$ for case $\mathrm{B}$, and $34.6^{\circ} \mathrm{C}$ for case $\mathrm{C}$. When all three mechanisms are presented (case D), the model essentially retains the original equilibrium solution.

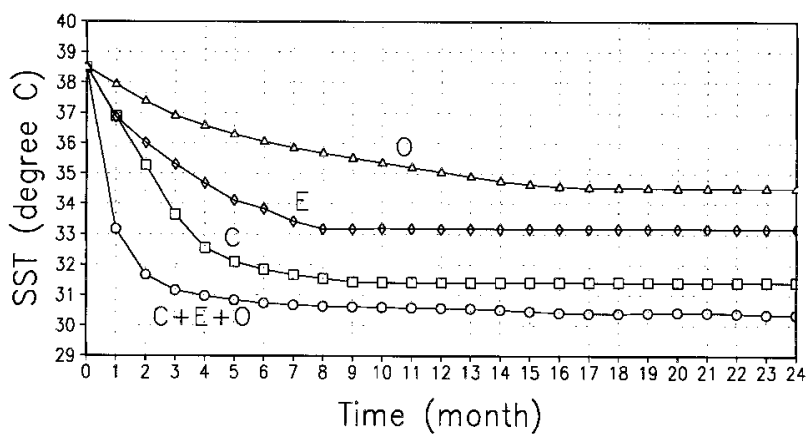

FIG. 9. Time evolution of maximum SST in the warm pool in the presence of cloud shortwave forcing only (denoted as $\mathrm{C}$ ), evaporation only $(\mathrm{E})$, ocean dynamics only $(\mathrm{O})$, and all of the above $(\mathrm{C}+\mathrm{E}+$ $\mathrm{O})$.

The above sensitivity experiments indicate that the cloud-SST feedback is a most important process in regulating maximum SSTs in the warm pool. The evaporation and ocean dynamics, on the other hand, can also effectively suppress the ocean warming. Overall, they are all essential in producing the observed climatological SSTs in the western Pacific.

The relative roles of clouds, surface evaporation, and ocean dynamics can be further revealed by comparing heat flux change rates with respect to SST changes. A particular question we address here is how much increase/decrease occurs in the shortwave radiation, surface evaporation, and ocean heat transport for an increase of $1^{\circ} \mathrm{C}$ in SST in the warm pool. (The SST anomaly pattern is kept the same for the moment.) The heat flux change rates are calculated based on a 30-day average, subtracted from the equilibrium solution in the control case (i.e., the annual-mean climate case). Figure 10 shows the calculated heat flux change rates. The resemblance of horizontal structure of the cloud shortwave forcing to the perturbed SST pattern implies that precipitation/convection is in phase with SST gradientinduced surface moisture convergence. The structures

\section{Initial SST Perturbation}

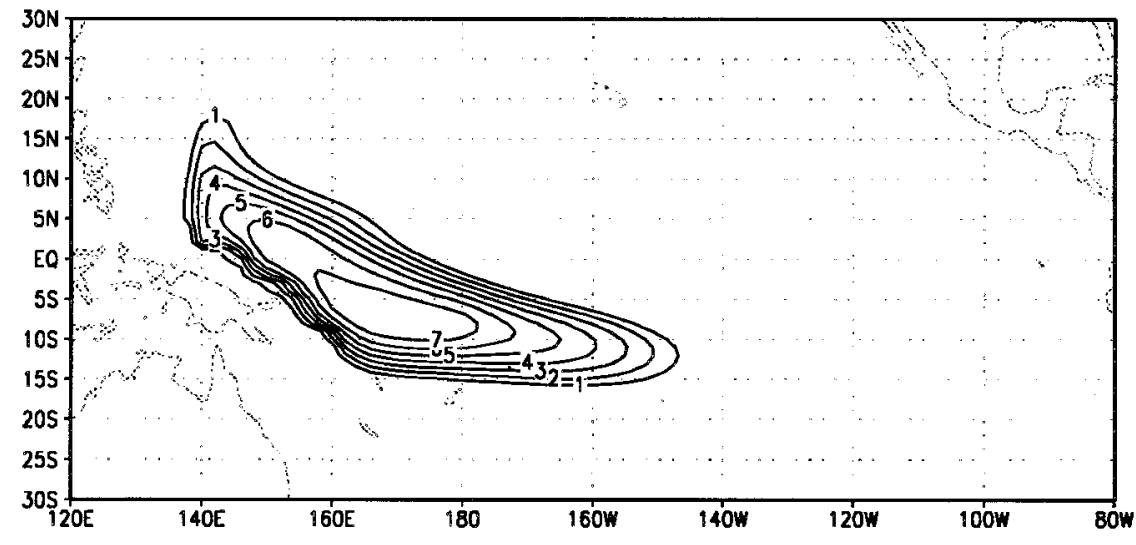

FIG. 8. Horizontal structure of a specified initial SST $\left({ }^{\circ} \mathrm{C}\right)$ perturbation [see Eq. (3.7)]. 

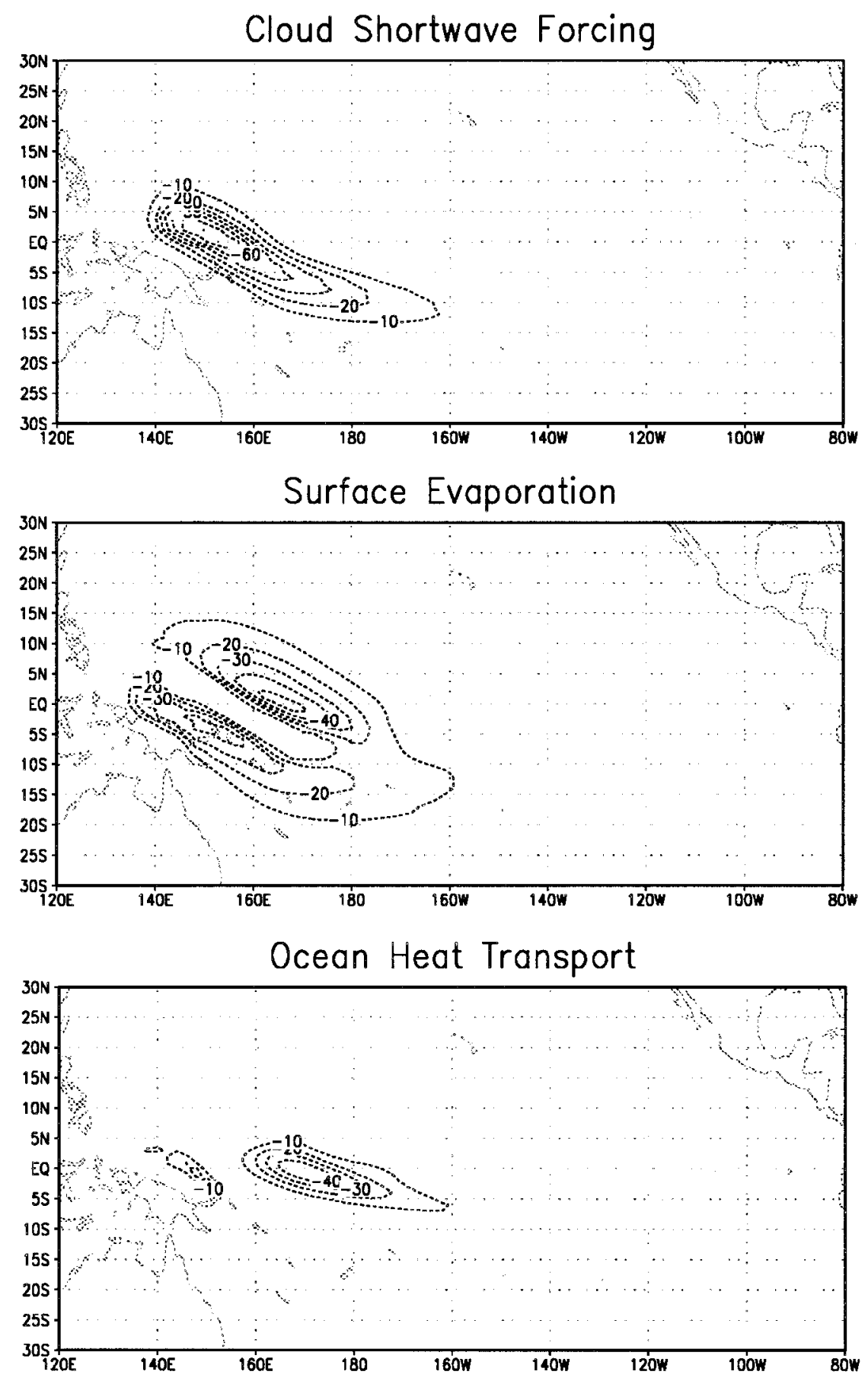

FIG. 10. Surface heat flux differences (units: $\mathrm{W} \mathrm{m}^{-2}$ ) between the perturbed SST cases and the control case in the presence of the cloud shortwave forcing, surface evaporation, and ocean dynamic processes. The amplitude of the SST perturbation in all three cases is $1^{\circ} \mathrm{C}$.

of the evaporative flux and ocean heat transport are complicated because of spatial phase differences among the SST, wind, and ocean currents. This is why maximum latent heat fluxes appear over large SST gradient regions away from the perturbed SST center. The increase of easterly winds to the east of the SST center cools the ocean through anomalous upwelling and zonal temperature advection.

The mean heat flux change rate over the warm pool region $\left(\bar{T} \geq 29^{\circ} \mathrm{C}\right)$ due to cloud shortwave forcing is 19.2 $\mathrm{W} \mathrm{m}^{-2} \mathrm{~K}^{-1}$, which is in good agreement with $\mathrm{Ra}$ manathan and Collins (1991). The averaged rates for 


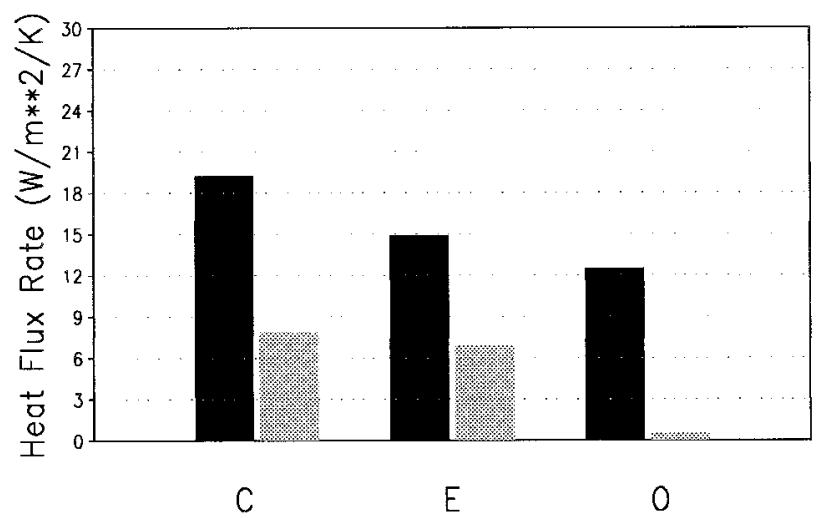

FIG. 11. The rates of heat flux change with respect to SST change for the cloud shortwave forcing (denoted as $\mathrm{C}$ ), surface evaporation $(\mathrm{E})$, and ocean dynamics $(\mathrm{O})$ (units: $\mathrm{W} \mathrm{m}^{-2} \mathrm{~K}^{-1}$ ) averaged over the western Pacific warm pool. The dark shaded bars are the cases where the initial SST perturbation is located in the warm pool [Eq. (3.7)], whereas the light shaded bars are the cases where a uniform SST perturbation is initially introduced.

evaporation and ocean heat transport are 14.9 and 12.5 $\mathrm{W} \mathrm{m}{ }^{-2} \mathrm{~K}^{-1}$, respectively (Fig. 11). These are somewhat larger than those estimated from the simple box model due to the constant wind speed assumption and the crude parameterization of ocean upwelling.

To examine the sensitivity of the model results to initial SST patterns, we conduct a set of parallel experiments in which we specify the following initial SST perturbation pattern:

$$
T^{\prime}= \begin{cases}\left(8^{\circ} \mathrm{C}\right) & \exp \left(-y^{2} / L_{y}^{2}\right) \cos \left(\pi x / 2 L_{x}\right), \\ & -L_{x}<x<L_{x} \\ 0, & \text { otherwise, }\end{cases}
$$

where $L_{y}=10^{\circ}, L_{x}=20^{\circ}$, and the $x$-axis origin is located at $170^{\circ} \mathrm{E}$ where maximum annual-mean SSTs appear. We particularly compared the simulated equilibrium SSTs in the two perturbed SST cases (Fig. 12). In general, the results agree. The largest discrepancy occurs in the ocean dynamics experiment, since ocean currents are mostly sensitive to the simulated surface winds, which depend heavily on SST patterns.

A common feature of the previous two perturbed SST patterns is that they all appear in the warm pool region. What happens in a greenhouse warming scenario in which a homogenous, rather than local, SST increase occurs? To answer this question, we conducted an experiment in which a uniform increase of $1{ }^{\circ} \mathrm{C}$ in the initial SST field is specified. The resulting heat flux changes differ significantly (see Fig. 11). The heat flux change rates of cloud shortwave forcing and surface evaporation decrease to about half of their original amplitudes while the rate due to ocean heat transport is negligible. Physical interpretation is as follows. Because of the uniform SST perturbation pattern, the SST gradients do not change. As a result, the surface winds are essentially the same. Therefore, ocean surface currents and tem-

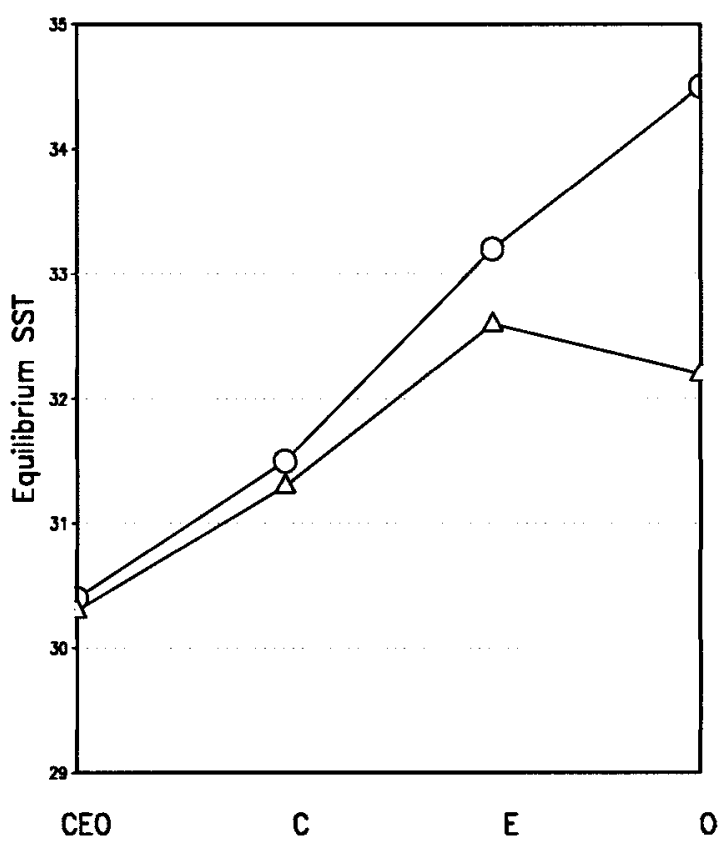

FIG. 12. Equilibrium SSTs simulated by the intermediate model in the presence of the cloud-SST feedback only (denoted by C), evaporation only (E), ocean dynamics only $(\mathrm{O})$, and all of the above $(\mathrm{C}$ $+\mathrm{E}+\mathrm{O})$. Circle and triangle curves denote the two initial SST perturbation cases with Eqs. (3.7) and (3.8), respectively.

perature advection are unchanged. On the other hand, the surface moisture content increases with the increased SSTs so that the total vertically integrated moisture convergence increases (even though the winds do not change). The increase is modest compared to the previous case when both winds and moistures are altered. This is why the cloud shortwave forcing is reduced. The change of the surface latent heat flux is attributed to the change of the air-sea specific humidity difference due to the SST change.

\section{Summary}

Due to the critical role of SSTs in the atmospheric greenhouse effect, a deeper understanding of the processes that limit maximum tropical SSTs is needed. In this study, a simple box model and an intermediate coupled atmosphere-ocean model are used to investigate the relative roles of clouds, surface evaporation, and ocean dynamics in regulating tropical SSTs.

So far, three SST regulation mechanisms have been proposed. They are cloud-SST feedback (Ramanathan and Collins 1991), evaporation-wind-SST feedback (Newell 1979; Wallace 1992; Fu et al. 1992), and ocean dynamics and heat transport (Sun and Liu 1996; Clement et al. 1996; Seager and Murtugudde 1997). Previously, each of the three mechanisms was proposed separately. Each mechanism was argued to be sufficient by itself to limit the SSTs within the observed range, therefore the others may not be necessary. In this study, we 
build a unified dynamic framework that combines the aforementioned three SST-regulation mechanisms so that we can investigate the relative importance of each process.

Our simple model analysis and intermediate coupled experiments indicate that all three mechanisms are essential in limiting the SSTs within the observed range. In the western Pacific warm pool, the largest contribution comes from the cloud shortwave radiation forcing followed by the effects of the surface evaporation and ocean dynamics. The lack of any one mechanism will lead to an equilibrium temperature that is too high, although unstable warming (due to the super greenhouse effect) will not occur in the presence of any one of the mechanisms.

Acknowledgments. The authors would like to thank Profs. Bin Wang and Tom Schroeder and the anonymous reviewers for their constructive comments. This study was supported by the Office of Naval Research and Naval Research Laboratory under program element 0601153N, by the National Science Foundation under Grant ATM-9613746, and by Frontier Research System for Global Change.

\section{APPENDIX}

\section{Governing Equations for the Intermediate Coupled Model}

The governing equations for the atmosphere are as follows (see Li and Wang 1994):

$$
\begin{aligned}
& E_{1} U-\beta y V=-g \rho_{a}^{-1} \frac{\partial P_{s}}{\partial x} \\
& E_{2} V+\beta y U=-g \rho_{a}^{-1} \frac{\partial P_{s}}{\partial y},
\end{aligned}
$$

where $U, V$, and $P_{s}$ denote zonal and meridional wind components and sea level pressure, respectively, and $E_{1}$ and $E_{2}$ are anisotropic, latitude-dependent Rayleigh friction coefficients whose values are given in Li and Wang (1994). The sea level pressure is determined from a vertically integrated hydrostatic equation for a moist hydrostatic atmosphere,

$$
\ln \left(\frac{P_{s}}{P_{u}}\right)=\frac{g}{R \gamma} \ln \left(\frac{T_{s}}{T_{s}-\gamma H}\right),
$$

where $P_{u}=100 \mathrm{mb}$ is the pressure at tropopause, $H=$ $16.8 \mathrm{~km}$ is the height of the tropopause, and the lapse rate $\gamma\left({ }^{\circ} \mathrm{C} \mathrm{km}^{-1}\right)$ is given by an empirical formula in terms of SST, $T_{s}\left({ }^{\circ} \mathrm{C}\right)$, that is,

$$
\gamma=10^{-3}\left[0.0956 T_{s}+3.54\right]
$$

Precipitation rate can then be determined by the sum of the boundary layer moisture convergence and local evaporation,
$P_{r}=\delta b\left[-\rho_{a} \Delta z \boldsymbol{\nabla} \cdot\left(q_{a} \mathbf{V}\right)+\rho_{a} c_{D}|\mathbf{V}|\left(q_{s}-q_{a}\right)\right]$,

where $c_{D}$ is the drag coefficient $(0.0015) ; \rho_{a}$ is surface air density $\left(1.2 \mathrm{~kg} \mathrm{~m}^{-3}\right) ; b$ is a precipitation efficiency coefficient $(0.75)$, which denotes the ratio of the precipitation to the total moisture convergence plus evaporation (Kuo 1974); and $\Delta z$ is the depth of the boundary layer $(1500 \mathrm{~m})$. The variable $\delta$ is a switch-on coefficient for SST-dependent nonlinear heating (Wang and $\mathrm{Li}$ 1993), which equals 1 when the total moisture convergence plus evaporation is positive and SST is greater than $26.5^{\circ} \mathrm{C}$, and equals 0 otherwise. The sea surface specific humidity $q_{s}$ is a function of SST and SLP, and the air surface specific humidity $q_{a}$ may be empirically determined from SST.

The governing equation for the upper-ocean mean currents, thermocline depth, and SST are (see Chang 1994):

$$
\begin{aligned}
\frac{\partial \mathbf{u}}{\partial t}+f \mathbf{k} \times \mathbf{u} & =-g^{\prime} \boldsymbol{\nabla} h+\frac{\boldsymbol{\tau}}{H}+\nu \nabla^{2} \mathbf{u}, \\
\frac{\partial h}{\partial t}+H \boldsymbol{\nabla} \cdot \mathbf{u}= & \nu \nabla^{2} h, \\
\frac{\partial T}{\partial t}+\mathbf{u}_{s} \cdot \boldsymbol{\nabla} T= & \frac{Q}{\rho c_{p} H_{s}}+\kappa \nabla^{2} T \\
& -\frac{1}{H_{s}} w_{e} M\left(w_{e}\right)\left(T-T_{\mathrm{sub}}\right),
\end{aligned}
$$

where the surface current $\mathbf{u}_{s}$ is determined from the Ekman shearing flow $\mathbf{u}_{e}$ and mean upper-ocean current u:

$$
\mathbf{u}_{s}=\mathbf{u}+\mathbf{u}_{e}\left(H-H_{s}\right) / H,
$$

and the Ekman flow $\mathbf{u}_{e}$ is given by

$$
r_{e} \mathbf{u}_{e}+f \mathbf{k} \times \mathbf{u}_{e}=\frac{\boldsymbol{\tau}}{H_{s}} .
$$

The entrainment velocity $w_{e}$ is determined as a divergence of the surface current

$$
w_{e}=H_{s} \boldsymbol{\nabla} \cdot \mathbf{u}_{s},
$$

and the temperature of entrained water beneath the base of the mixed layer, $T_{\text {sub }}$ is parameterized in terms of changes in the thermocline depth, that is,

$$
T_{\text {sub }}=25+0.16(h-H) .
$$

The step function $M(x)$, which equals 1 when $x>0$ and equals 0 when $x<0$, describes the asymmetry of ocean upwelling/downwelling in changing the SST.

The model parameters used in the present study have the following values: reduced gravity $g^{\prime}=4.17 \mathrm{~cm} \mathrm{~s}^{-2}$, surface mixed layer depth $H_{s}=50 \mathrm{~m}$, mean thermocline depth $H=150 \mathrm{~m}$, surface Ekman layer Rayleigh friction coefficient $r_{e}=1$ day $^{-1}$, and eddy viscosity and diffusivity coefficients $\nu=\kappa=10^{4} \mathrm{~m}^{2} \mathrm{~s}$. 


\section{REFERENCES}

Anderson, D. L. T., and J. P. McCreary, 1985: Slowly propagating disturbances in a coupled ocean-atmosphere model. J. Atmos. Sci., 42, 615-629.

Arking, A., and D. Ziskin, 1994: Relationship between clouds and sea surface temperatures in the western tropical Pacific. J. Climate, 7, 988-1000.

Bjerknes, J., 1969: Atmospheric teleconnections from the equatorial Pacific. Mon. Wea. Rev., 97, 163-172.

Budyko, M. I., and D. H. Miller, 1974: Climate and Life. Academic Press, $508 \mathrm{pp}$.

Cane, M. A., 1979: The response of an equatorial ocean to simple wind stress patterns. I: Model formulation and analytic results. J. Mar. Res., 37, 233-252.

- and S. E. Zebiak, 1985: A theory for El Niño and the Southern Oscillation. Science, 228, 1084-1087.

Chang, P., 1994: A study of seasonal cycle of sea surface temperature in the tropical Pacific Ocean using reduced gravity models. $J$. Geophys. Res., 99 (C4), 7725-7741.

Clement, A., R. Seager, M. A. Cane, and S. E. Zebiak, 1996: An ocean dynamical thermostat. J. Climate, 9, 2190-2196.

Fu, R., A. D. Del Genio, W. B. Rossow, W. T. Liu, 1992: Cirruscloud thermostat for tropical sea surface temperature tested using satellite data. Nature, 358, 394-397.

Graham, N. E., and T. P. Barnett, 1987: Sea surface temperature, surface wind divergence, and convection over the tropical oceans. Science, 238, 657-659.

Hartmann, D. L., and M. Michelsen, 1993: Large-scale effects on the regulation of tropical sea surface temperature. J. Climate, $\mathbf{6}$, 2049-2062.

Kiehl, J. T., and B. P. Briegleb, 1992: Comparison of observed and calculated clear sky greenhouse effect: Implications for climate studies. J. Geophys. Res., 97, 10 037-10 049.

Kuo, H.-L., 1974: Further studies of the parameterization of the influence of cumulus convection on large-scale flow. J. Atmos. Sci., 31, 1231-1240.

Laszlo, I., and R. T. Pinker, 1993: Shortwave cloud-radiative forcing at the top of the atmosphere at the surface and of theatmospheric column as determined from ISCCP C1 data. J. Geophys. Res., 98, 2703-2713.

Li, T., 1997a: Air-sea interactions of relevance to the ITCZ: Analysis of coupled instability and experiments in a hybrid coupled GCM J. Atmos. Sci., 54, 134-147.

_ 1997b: Phase transition of the El Niño-Southern Oscillation: A stationary SST mode. J. Atmos. Sci., 54, 2872-2887.

—, and S. G. H. Philander, 1996: On the annual cycle of the equatorial eastern Pacific. J. Climate, 9, 2986-2998.

—, and B. Wang, 1994: A thermodynamic equilibrium climate model for monthly mean surface winds and precipitation over the tropical Pacific. J. Atmos. Sci., 51, 1372-1385.

Lindzen, R. S., and S. Nigam, 1987: On the role of sea surface temperature gradients in forcing low level winds and convergence in the tropics. J. Atmos. Sci., 44, 2240-2458.

Liou, K. N., 1980: An Introduction to Atmospheric Radiation. Academic Press, 392 pp.

Liu, W. T., A. Zhang, and J. K. B. Bishop, 1994: Evaporation and solar irradiance as regulators of sea surface temperature in annual and interannual changes. J. Geophys. Res., 99, 12 623-12 637.

Liu, Z., and B. Huang, 1997: A coupled theory of tropical climatology: Warm pool, cold tongue, and Walker circulation. J. Climate, 10, 1662-1679.

Neelin, J. D., 1991: The slow sea surface temperature mode and the fast-wave limit: Analytic theory for tropical interannual oscillation and experiments in a hybrid coupled model. J. Atmos. Sci. 48, 584-606.

Newell, R. E., 1979: Climate and the ocean. Amer. Sci., 67, 405416.

Oberhuber, J. M., 1988: An atlas based on the "COADS" data set: The budget of heat, buoyancy, and turbulent kinetic energy at the surface of the global ocean. Max-Planck Institut fur Meteorologie Rep. 15, 196 pp.

Payne, R. E., 1972: Albedo of the sea surface. J. Atmos. Sci., 29, 959-970.

Philander, S. G. H., D. Gu, D. Halpern, G. Lambert, G. Lau, T. Li, and R. C. Pacanowski, 1996: Why the ITCZ is mostly north of the equator. J. Climate, 9, 2970-2985.

Pinker, R. T., and I. Laszlo, 1992: Modeling surface solar irradiance for satellite applications on a global scale. J. Appl. Meteor., 31, 194-211.

Ramanathan, V., and W. Collins, 1991: Thermodynamic regulation of ocean warming by cirrus clouds deduced from observations of the 1987 El Niño. Nature, 351, 27-32.

- and 1992: Thermostat and global warming. Nature, 357, 649-650.

Schneider, N., T. Barnett, M. Latif, and T. Stockdale, 1996: Warm pool physics in a coupled GCM. J. Climate, 9, 219-239.

Seager, R., S. E. Zebiak, and M. A. Cane, 1988: A model of the tropical Pacific sea surface temperature climatology. J. Geophys. Res., 93, 1265-1280.

— , and R. Murtugudde, 1997: Ocean dynamics, thermocline adjustment, and regulation of tropical SST. J. Climate, 10, 521534.

Sun, D.-Z., 1997: El Niño: A coupled response to radiative heating? Geophys. Res. Lett., 24, 2031-2034.

— mostat for the Tropics. Science, 272, 1148-1150.

Waliser, D. E., 1996: Formation and limiting mechanisms for very high sea surface temperature: Linking the dynamics and the thermodynamics. J. Climate, 9, 161-188.

—, and N. E. Graham, 1993: Convective cloud systems and warmpool sea surface temperature: Coupled interactions and self-regulation. J. Geophys. Res., 98, 12 881-12 893.

Wallace, J., 1992: Effect of deep convection on the regulation of tropical sea surface temperature. Nature, 357, 230-231.

Wang, B., and T. Li, 1993: A simple tropical atmospheric model of relevance to short-term climate variations. J. Atmos. Sci., 50, 260-284.

- and — and P. Chang, 1995: An intermediate model of the tropical Pacific ocean. J. Phys. Oceanogr., 25, 1599-1616.

Xie, P. P., and P. A. Arkin, 1996: Analyses of global monthly precipitation using gauge observations, satellite estimates and numerical model prediction. J. Climate, 9, 804-858.

Zebiak, S. E., and M. A. Cane, 1987: A model ENSO. Mon. Wea. Rev., 115, 2262-2278 